\title{
MODEL PEMBELAJARAN BAHASA BALI YANG LEBIH BERMAKNA
}

\author{
Anak Agung Gde Putera Semadi \\ Program Studi Pendidikan Bahasa Indonesia Dan Daerah Fakultas Keguruan Ilmu \\ Pendidikan (FKIP), Universitas Dwijendra. \\ Email : puterasemadi60@gmail.com
}

\begin{abstract}
Abstrak
Pada era informasi dan digitalisasi sekarang ini bahasa, aksara, dan sastra Bali masih tetap hidup dan dipelihara dengan baik oleh penutur masyarakat suku Bali. Sebagai aspek kebudayaan Bali tentunya bahasa Bali memegang peranan sangat penting dalam menunjang kebudayaan nasional. Oleh karena itu, maka model dan strategi pembelajaran bahasa daerah Bali ke depan perlu terus dikaji dan diteliti dari berbagai perspektif yang komunikatif-interaktif, inovatif, intergralistik, lebih menarik dan bermakna. Penelitian ini tergolong jenis penelitian kualitatif/normatif yang dirancang sebagai suatu bagian dari pendekatan penomenologis. Objek kajiannya pada teks serta konteksnya yang ada di masyarakat. Hasil studi pustaka dan data empiris yang telah diklasifikasi dikaji dengan menggunakan pendekatan kultural, pendekatan manajerial, dan pendekatan keteladanan. Penentuan informan dilakukan dengan teknik purposive random sampling dan dikembangkan dengan teknik snowball. Sumber data diperkuat pula dengan instrumen penelitian berupa pedoman observasi partisipasi, wawancara, rekaman, serta studi dokumen. Melalui aplikasi metode analisis deskriptif diperoleh hasil penelitian yang cukup memadai yakni untuk mewujudkan model pembelajaran bahasa Bali yang lebih menarik dan bermakna dapat dirumuskan melalui empat strategi yaitu bermain kata, bermain peran, kuis bahasa dan sastra Bali, dan olah (utak-atik) aksara Bali. Selain itu, dapat pula dilengkapi dengan menerapkan pendekatan Contextual Teaching and Learning, Komunikatif - Interaktif, dan terintegralistik.
\end{abstract}

Kata kunci : Model Pembelajaran, Bahasa Bali.

\begin{abstract}
In the current era of information and digitalization, Balinese language, script and literature are still alive and well preserved by Balinese speakers. As an aspect of Balinese culture, of course the Balinese language plays a very important role in supporting national culture. Therefore, the models and strategies for learning Balinese regional languages in the future need to be continuously studied and researched from various communicativeinteractive, innovative, interactive, more interesting and meaningful perspectives. This research was classified as a qualitative / normative research type which was designed as a part of the phenomenological approach. The object of study was the text and its context in society. The results of literature studies and classified empirical data were examined using a cultural approach, a managerial approach, and an exemplary approach. Determination of informants was carried out using purposive random sampling technique and was developed using snowball techniques. Data sources were also strengthened by research instruments in the form of participatory observation guidelines, interviews, recordings, and document studies. Through the application of the descriptive analysis method, adequate research results were obtained, namely to realize a more interesting and meaningful Balinese language learning model that could be formulated through four strategies, namely playing words, role playing, Balinese language and literature quizzes, and processing (tinkering) Balinese characters. . In addition, it can also be complemented by applying a Contextual Teaching and Learning approach, Communicative - Interactive, and integrated.
\end{abstract}

Keywords: Learning Model, Balinese Language. 


\section{PENDAHULUAN}

Krisis multidimensional berkepanjangan yang merundung bangsa ini adalah bermula dari krisis moralitas. Krisis itu terjadi ketika seseorang tidak pernah merasa puas terhadap kekuasaan, kekayaan, dan nafsu yang tega mengorbankan milik bangsa untuk kepentingan pribadi atau kelompok tertentu. Efek yang kemudian ditimbulkan dari kriisis itu adalah terjadinya kerusuhan di mana-mana dan diberbagai sektor kehidupan seperti: politik, ekonomi, sosial-budaya, dan agama. Dari permasalahan tersebut, maka seolah-olah telah terjadi kehilangan rasa kemanusiaan dan kemampuan mengendalikan diri baik secara individu maupun kolektif. Akhirnya, menimbulkan tindakan tidak senonoh yang merambah kepada generasi anak bangsa berupa kekerasan fisik, kekerasan mental, bahkan kekerasan seksual.

Berangkat dari beberapa permasalahan di atas, maka selanjutnya "Pendidikan dan Pengajaranlah" yang sering dituding lemah sehingga selalu menjadi problematik yang hangat digunjingkan. Bahkan lebih fokus daripada itu, yang sering disoroti dan dipertanyakan adalah aspek-aspek yang ada relevansinya dengan kualitas/mutu karakter atau budi pekerti yang dikembangkan di berbagai media pendidikan terutama di pendidikan formal (SD, SMP, sampai dengan ke jenjang SMA/SMK). Bagaimanakah implementasi model pendidikan dalam proses pembelajaran yang berlangsung di sekolah-sekolah?. Apakah terintegrasi dengan materi pelajaran yang berhubungan dengan pendewasaan karakter peserta didik?

Pembelajaran bahasa, akasara, dan sastra Bali memiliki peranan yang sangat besar dalam menumbuhkembangkan kepribadian unggul generasi milinea Bali ke depan. Beragam naskah kuna/sastra Bali purwa menyimpan segudang nilai kehidupan sosial budaya adiluhung universal yang dapat meningkatkan mutu kepribadian bangsa serta membanghkitkan peradaban Bali di tengah-tengah pesatnya perkembangan kebudayaan nasional 
yang progresif - inovatif. Apabila dalam proses pembelajaran bahasa, aksara, dan sastra Bali masih sepenuhnya menggunakan pola pembelajaran yang monoton tradisional tanpa disertai dengan implementasi model-model pembelajaran yang terintergrasi, maka tentu akan sulit mencapai sasaran yang diinginkan. Proses pembelajaran itu akan menjadi sangat membosankan bahkan akan semakin dianggap tidak begitu penting di era pembaharuan yang serba cepat ini. Oleh karena itu, maka khusus untuk model pembelajaran bahasa Bali di berbagai media dan jenjang pendidikan perlu ditingkatkan agar menjadi semakin bermakna. Pembelajaran bahasa Bali dapat menguatkan eksistensi kebudayaan (lokal - nasional) umumnya dan karakter unggul setiap peserta didik pada khususnya. Dengan demikian, maka peran pembelajaran bahasa Bali menjadi lebih bermakna dalam menuntun kepribadian serta mengatasi krisis moraliats. Ini bertujuan untuk menemukan celah, kekuatan, dan kelemahan. Sangat membantu penelitian ini untuk mengisi kekosongan dan menjadi penelitian yang berbeda (Wayan Swarniti, 2019).

\section{METODE}

Penelitian ini tergolong jenis penelitian kualitatif/normatif yang dirancang sebagai suatu bagian dari pendekatan penomenologis. Objek kajiannya pada teks serta konteksnya yang ada di masyarakat. Penelitian kualitatif tergolong sebagai prosedur penelitian yang menghasilkan data deskriptif berupa kata-kata serta gambar yang pada prinsipnya dapat diamati dan dideskripsikan dengan jelas tanpa menggunakan prosedur-prosedur statistik atau dengan cara kuantifikasi lainnya.

Data dari hasil studi pustaka dan data empiris yang telah diklasifikasi dikaji dengan menggunakan pendekatan kultural (cultural approach), pendekatan manajerial (managerial approach), dan pendekatan keteladanan (behavioral model approach). Ketiga pendekatan ini dilaksanakan secara intergratif dan saling melengkapi guna mendapatkan/menghasilkan kepribadian peserta didik yang lebih luhur dan bermartabat. Metode ini telah dilaksanakan oleh Show Women School di Tokyo, Jepang. 
Untuk memeroleh uraian yang tajam, mendalam, logis, dan sistematis, maka aplikasi metode analisis deskriptif dalam kesempatan ini jelas tidak dapat dihindari. Penentuan informan dilakukan dengan teknik purposive random sampling dan dikembangkan dengan teknik snowball. Sumber data diperkuat pula dengan instrumen penelitian berupa pedoman observasi partisipasi, pedoman wawancara mendalam, rekaman, serta studi dokumen.

\section{HASIL DAN PEMBAHASAN}

Pembahasan ini akan diawali dari deskripsi tentang misi dan tujuan pengajaran bahasa daerah (Bali). Setelah itu berturut-turut diuraikan mengenai payung hukum / kebijakannya, fungsi pengajarannya, kekuatan, kelemahan, peluang, dan tantangannya, serta yang terakhir adalah pembelajaran bahasa Bali yang lebih bermakna.

\subsection{Misi dan Tujuan Pengajaran}

Salah satu misi dari pembelajaran bahasa Bali adalah menyelenggarakan pendidikan dan pengajaran bahasa, aksara, sastra Bali yang berkaitan dengan budaya Bali.
Tujuan pendidikan ini adalah untuk menghasilkan lulusan yang bermutu dan bertakwa kepada Tuhan Yang Maha Esa, sehingga dapat mengaplikasikannya dalam lingkuangan kehidupan keluarga dan masyarakat. Pendidikan ini dapat menghasilkan lulusan yang kolaboratif, kompetitif, berkarakter, dan berbudaya. Selain itu, tujuan dari penyelenggaraan pendidikan dan pengajaran bahasa Bali adalah melaksanakan pengajaran dan pengembangan dalam bidang bahasa, aksara, sastra, dan budaya Bali yang inovatif, serta melakukan diseminasi hasil-hasil pengajaran demi kepentingan pengembangan dunia pendidikan dan masyarakat.

Dalam sejarah pengajaran bahasa daerah, seperti survei tahun 1999 (Rusyana dalam Rosidi,ed., 1999:72-75) ada disebutkan bahwa Bali termasuk salah satu dari lima belas provinsi di Indonesia yang bahasa daerahnya diajarkan di sekolah-sekolah. Empat belas provinsi lainnya yang mengajarkan bahasa daerahnya adalah Aceh, Sumatra Utara, Bengkulu, Lampung, Jawa Barat, Jawa Tengah, DIY, Jawa Timur, Kalimantan Barat, Kalimantan Selatan, Kalimantan Timur, Sulawesi Utara, 
Sulawesiu Selatan, dan Sulawesi Tenggara. Provinsi lain yang kemudian menyusul yaitu Sumatra Barat, Sumatra Selatan, Jakarta, Papua, dan Nusa Tenggara Timur. Menurut Wibawa bahasa-bahasa daerah yang diajarkan adalah bahasa Aceh, Gayo, Batak Mandaliling, Batak Toba, Batak Simalungun, Batak Karo, Batak Melayu, Rejang, Lampung, Sunda,Cirebon, Madura, Dayak Simpang, Dayak Kanayatan, Banjar, Kutai, Tombulu, Tonsawang, Mongondow, Bugis, Makasar, Mandar, Toraja, Tolaki, Muna, Wolio, dan bahasa Bali untuk di Bali diajarkan sampai ke tingkat SLTA (Mulyana, ed.,2008:32).

\subsection{Payung Hukum / Kebijakan}

Garis pembinaan dan pengembangan bahasa daerah di Indonesia tunduk pada kebijakan pembinaan dan pengembangan bahasa daerah. Pembinaan dan pengembangan bahasa daerah dapat dirunut mulai dari Sumpah Pemuda 1928. Bunyi Sumpah Pemuda yang terkait dengan bahasa daerah adalah "Kami putra-putri Indonesia menjunjung bahasa persatuan Bahasa Indonesia”. Menurut Sutrisna
Wibawa (2008) bunyi pernyataan ini berrarti bahwa secara implisit Sumpah Pemuda mengakui keberadaan bahasa daerah. Dalam Perubahan Keempat UUD 1945 Bab XIII, Pasal 32, dinyatakan: (1) negara memajukan Kebudayaan Nasional Indonesia di tengah-tengah peradaban dunia dengan menjamin kebebasan masyarakat dalam memelihara dan mengembangkan nilainilai budayanya, dan (2) negara menghormati dan memelihara bahasa daerah sebagai kekayaan budaya nasional. Dalam konteks (kongres) bahasa Bali, kata menghormati dapat diartikan bahwa bahasa Indonesia dan bahasa Bali mempunyai kedudukan yang sejajar, tidak saling mendominasi atau saling mematikan. Para penutur bahasa Indonesia di Bali dan para penutur bahasa Bali agar memiliki kemampuan dwi-bahasa. Sedangkan kata memelihara artinya negara (legislatif, eksekutif, dan yudikatif) turut menjaga kelestarian bahasa Bali melalui pemamfaatan SDM, dana, material, dan teknologi serta penetapan kebijakan publik. UUD 45 hasil amendemen juga menyebutkan: (a) Pasal 28 (3) : Identitas budaya dan hak masyarakat tradisonal dihormati selaras 
dengan perkembangan jaman dan peradaban. (b) Pasal 31 (3) : Pemerintah mengusahakan dan menyelenggarakan satu sistem pendidikan nasional. (c) Pasal 31 (5): Pemerintah memajukan ilmu pengetahuan dan teknologi. (d) Pasal 32 (1) : Negara memajukan kebudayaan nasional Indonesia.

$$
\text { Selanjutnya dalam Undang- }
$$

Undang Nomor 22 Tahun 1999 tentang Otonomi Daerah yang dijabarkan lagi ke dalam Peraturan Pemerintah Nomor 25 Tahun 2000, dinyatakan bahwa pengembangan bahasa dan budaya daerah yang merupakan bagian dari bidang pendidikan dan kebudayaan menjadi kewenangan Pemerintah Provinsi. Peraturan Daerah No 3 Tahun 1992 : tentang Bahasa, Aksara, dan Sastra Bali. Pergub Bali No 80 Tahun 2018 tentang Perlindunghan dan Penggunaan Bahasa, Aksara, Sastra Bali, dan Penyelenggaraan Bulan Bahasa Bali. Keluarnya Pergub No 80 Tahun 2018 ini didadasarkan atas : realitas kian melunturnya penggunaan bahasa, aksara, dan sastra Bali di kalangan masyarakat. Adanya penggerusan budaya Bali itu karena pengaruh modernisasi, teknologi, dan globalisasi (Wayan Koster, dalam
Bali Post, senen 22 Oktober 2018, hal: 1). Ketetapan Unesco Tanggal 17 Nopember 1999 tentang bahasa internasional bahasa ibu setiap tanggal 21 Februari.

Berdasarkan beberapa bentuk kebijakan hukum di atas, maka selanjutnya dapat dikatakan bahwa pendidikan dan pengajaran bahasa Bali sebagai bahasa yang mencerminkan identitas budaya Bali wajib ditingkatkan searah dan sejajar dengan perkembangan wujud perubahan kebudayaan yang kian pesat terjadi di era global ini. Dari pernyataan-pernyataan yang tersebut dalam kebijakan-kebijakan hukum itu dapat diartikan bahwa pendidikan dan pengajaran bahasa Bali termasuk aksara dan sastranya berpotensi besar dalam memertahankan sekaligus mengenmbangkan nilai-nilai budaya adiluhung Bali guna membangun peradaban Bali yang lebih kokoh di masa depan.

\subsection{Fungsi Pengajaran}

Dilihat dari sudut pandang politik bahasa nasional dan kajian terhadap fungsi bahasa, maka pengajaran bahasa daerah (baca: Bali) setidaknya diarahkan pada tiga fungsi pokok, yaitu 
(1) berfungsi sebagai alat komunikasi,

(2) fungsi edukatif, dan (3) fungsi kultural.

\subsubsection{Fungsi Komunikasi}

Pengajaran bahasa Bali yang
berfungsi sebagai alat komunikasi
diarahkan agar siswa dapat
menggunakan bahasa Bali secara baik
dan benar untuk keperluan alat
berinteraksi dalam keluarga dan
masyarakat (tentunya sesuai dengan
tingkatan-tingkatan bahasa Bali yang
disebut dengan anggah ungguh basa
Bali). Fungsi pengajaran ini
mengandung nilai-nilai kearifan lokal
hormat atau sopan santun di antara para
pembicatra, yaitu orang yang berbicara,
orang yang diajak berbicara, dan orang
yang dibicarakan.

\subsubsection{Fungsi Edukatif}

Pengajaran bahasa Bali yang berfungsi edukatif diarahkan agar peserta didik drapat memeroleh nilai-nilai budaya daerah untuk keperluan pembentukan kepribadian dan identitas bangsa melalui penggunaan anggahungguh dalam bahasa Bali. Menerapkan anggah-ungguh basa, berarti pula menanamkan nilai-nilai sopan santun pada siswa. Fungsi edukatif ini dapat pula dilakukan melalui pemahaman terhadap karya-karya sastra Bali Purwa/kuna, baik dalam aktivitas sekaa pasantian maupun yang ada dalam seni pertunjujkan. Fungsi edukatif dalam seni pertunjukan selain untuk tontonan sekaligus sebagai tuntunan. Dalam khasanah bahasa dan sastra Bali banyak tersimpan nilai lokal yang dapat digunakan untuk mengembangkan fungsi edukatif terutama fungsi untuk pembentukan kepribadian.

\subsubsection{Fungsi Kultural}

Pengajaran bahasa Bali yang berfungsi kultural diarahkan untuk menggali dan menanamkan kembali nilai-nilai budaya daerah sebagai upaya untuk membangun identitas dan menanamkan filter dalam menyeleksi datangnya pengaruh budaya luar. Jika fungsi komunikasi dan edukatif sudah terlaksana dengan baik, maka sebenarnya pengajaran yang berfungsi kultural akan dapat tercapai, karena sesungguhnya fungsi kultural terkait langsung dengan kedua fungsi itu. Jelasnya, melalui fungsi alat komunikasi dan edukatif diharapkan telah ditanamkan nilai-nilai budaya 
daerah Bali yang siap membangun identitas budaya yang kuat, dan yang pada akhirnya dapat membendung dan memfilter pengaruh budaya luar.

\subsection{Kekuatan, Kelemahan, Peluang, dan Tantangan}

\subsubsection{Kekuatan}

Beberapa payung hukum yang telah dideskripsikan pada butir $2.1 \mathrm{di}$ atas (dimulai dari Sumpah Pemuda 1928 sampai dengan Pergub Nomor 80 tahun 2018 dan juga Ketetapan Unesco 17 Nopember 1999) merupakan kekuatan yang menandakan bahwa betapa pentingnya pengajaran Bahasa, Aksara, dan Sastra daerah (Bali) secara formal di setiap jenjang pendidikan di Bali. Upaya ini mencerminkan penanaman nilai-nilai budaya khususnya yang bertalian dengan bidang perlindungan, pelestarian, pembinaan, dan pengembangan bahasa, akasa, dan sastra Bali itu sendiri.

Pemerintah Provinsi Bali melalui Dinas Pendidikan Pemuda dan Olah Raga, Dinas Kebudayaan, dan Lembaga Perlindungan Bahasa, Aksara, dan Sastra Bali menindaklanjuti kebijakan-kebijakan itu dengan berbagai aktivias antara lain mengadakan seleksi perekrutan Tenaga Penyuluh Bahasa Bali
Non PNS, melaksanakan bulan bahasa Bali, mengadakan pembinaan Bahasa, aksara, dan sastra Bali ke seluruh Kabupaten/ Kota di Bali, serta mnyelenggarakan Pendidikan Profesi Guru (PPG) (Bahasa Bali) dalam jabatan. Demikian juga kegiatan-kegiatan yang bertalian dengan bidang perlindungan dan pelestarian seperti pasamuhan agung (kongres) bahasa, aksara, dan sastra Bali secara periodik, lomba nyastra, pasantian, nyurat lontar, dan lain-lain.

Di lembaga-lembaga pendidikan formal dari SD sampai dengan SLTA dan juga Perguruan Tinggi (terutama yang memiliki prodi bahasa daerah), bahasa Bali telah menjadi pelajaran wajib untuk diajarkan. Setiap Kabupaten/Kota memiliki kelompok Musyawarah Guru Mata Pelajaran (MGMP) tingkat SMP dan SLTA untuk mata pelajaran bahasa Bali sebagai mata pelajaran muatan lokal. Buku-buku pelajaran bahasa Bali, Pasang Aksara Bali, Pedoman Penulisan Aksara Bali, karya-karya sastra-sastra Bali purwa dan anyar baik yang berupa tembang maupun gancaran sudah banyak diterbitkan sebagai pendukung proses pembelajaran bahasa Bali.

\subsubsection{Kelemahan}


Walaupun cukup banyak payung hukum/kebijakan sebagai bentuk upaya perlindungan, pelestarian, pembinaan, dan pengembangan bahasa Bali, namun tidak dapat dipungkiri bahwa dalam kaitannya dengan implementasi pengajaran bahasa Bali masih terdapat beberapa kelemahan, yaitu :

1. Masih ada perbedaan latar belakang kemampuan guru bahasa Bali dalam memahami bahasa Bali serta berkomunikasi dengan bahasa Bali yang baik dan benar (secara tertulis dan lisan) sehingga minat dan sikapnya dalam mengajarkan peserta didik dalam berbahasa Bali menjadi kurang menarik.

2. Peserta didik masih terlihat lebih dominan mempelajari konsep kebahasaan dan kesastraan daripada belajar keterampilan berbahasa Bali.

3. Selama ini persediaan buku-buku bahasa Bali dan referensinya yang dibutuhkan oleh guru-guru dan peserta didik untuk memantapkan proses pembelajaran bahasa, aksara, dan sastra Bali belum tersebar secara merata di seluruh jenjang pendidikan di Bali.
4. Pemahaman dan Implementasi kurikulum yang masih simpang siur dan sering ber-

ubah-ubah.

5. Jumlah jam pelajaran bahasa Bali masih terbatas; hanya 2 jam dalam seminggu. Hal ini menyebabkan perolehan bahasa Bali dalam pembelajaran bahasa Bali oleh peserta didik menjadi sangat terbatas. Bahkan sangat memengaruhi rendahnya kualitas kemampuan peserta didik memahami bahasa Bali baik secara teoritis maupun praktis.

6. Proses pembelajaran bidang studi bahasa Bali yang berlangsung sering tidak diarahkan ke kontreksnya (tidak kontekstual).

7. Pembelajaran bahasa Bali sekarang ini kurang disajikan dalam konteks multikultural.

8. Minat generasi milenia Bali mempelajari bahasa Bali di era global sangat sedikit. Sering ada wacana yang menyebutkan terbatasnya lapangan pekerjaan sehingga kurang menjamin masa depan para lulusan bahasa Bali untuk memeroleh pekerjaan. 


\subsubsection{Peluang}

Pada dasarnya bahasa Bali yang masuk sebagai mata pelajaran muatan lokal dan wajib diajarkan di setiap jenjang pendidikan dapat memberi peluang yang cukup besar bagi Perguruan Tinggi / Sekolah Tinggi yang memiliki jurusan / prodi Bahasa dan Seni atau Bahasa Daerah Bali. Sudah jelas sebagai lembaga pendidikan tenaga kependidikan akan memberi kesempatan kepada lulusan SLTA yang berminat menjadi guru yang profesional dalam mengajarkan bahasa Bali secara formal di sekolah. Selain itu, bisa menjadi penutur-penutur yang baik di masyarakat, penerjemah, penulis dan penyadur lontar yang andal, penulis aksara dan lambang-lambang aksara yang berhubungan dengan yadnya, serta tenaga penyuluh bahasa Bali yang profesional di tengah-tengah masyarakat.

Oleh karena pengetahuan bahasa, aksara, dan sastra Bali bersumber dari banyak naskah sastra lama yang berhubungan dengan nilai-nilai luhur peradaban dan kebudayaan Bali, maka para sarjana lulusan Pendidikan Bahasa, Aksara, dan Sastra Bali juga memiliki peluang yang besar untuk menjadi tenaga-tenaga penyuluh kebudayaan yang profesional.

\subsubsection{Tantangan}

Setelah dicermati dengan baik, ternyata pengajaran bahasa Bali di sekolah-sekolah merupakan salah satu dari proses transpformasi budaya Bali yang sudah berlangsung sejak dahulu. Meskipun demikian, hingga kini keadaannya diwarnai oleh berbagai tantangan yang setidaknya dapat mengurangi kelancaran pelaksanaan pendidkian dan pengajaran bahasa Bali itu sendiri. Beberapa tantangan yang sedang dihadapi antara lain :

1. Masih banyak penggunaan anggah ungguh basa Bali yang kurang tepat sehingga dianggap sulit digunakan untuk berkomunikasi terutama kepada lawan bicara yang status sosialnya berbeda atau lebih tinggi.

2. Perbendaharaan kosa kata bahasa Bali yang masih terbatas sehingga sedikit kesulitan mencari padanan kosa kata bahasa lain (Indonesia dan asing misalnya) dalam bahasa Bali.

3. Belum ditemukan media yang efektif dan menarik bagi peserta didik dalam belajar bahasa Bali, yang dapat 
digunakan oleh setiap guru dengan kualifikasi yang berbeda.

4. Pihak sekolah belum dapat menyadari sepenuhnya tentang betapa pentingnya menjadikan bahasa Bali sebagai mata pelajaran yang menentukan.

5. Pemahaman dan praktik terhadap empat keterampilan berbahasa dalam pembelajaran bahasa Bali belum berimbang.

6. Menulis aksara Bali masih dipandang sulit disebabkan karena pemahaman terhadap pedoman penulisan aksara Bali belum begitu mendalam, sehingga tidak jarang terdapat hasil penulisan yang berbeda satu sama lain.

\subsection{Pembelajaran Bahasa Bali yang Bermakna dan \\ Menarik}

Salah satu upaya untuk menumbuhkan kembali semangat dan rasa cinta generasi muda Bali terhadap bahasa, aksara, dan sastra Bali adalah dengan mengajarkan bahasa, aksara, dan sastra Bali itu di lembaga pendidikan formal. Agar proses pembelajarannya dapat berlangsung dengan baik, tidak membosankan, dan menarik, maka pengajaran bahasa Bali itu dapat dilakukan dalam bentuk mata pelajaran tersendiri, bukan perwujudan muatan lokal. Atau mungkin proses pembelajaran bahasa Bali itu dapat juga dilakukan secara terintergrasi dengan mata pelajaran-mata pelajaran yang lain. Dalam pembelajaran bahasa Bali diperlukan model pembelajaran yang lebih bermakna dan menarik agar benarbenar menjadi materi pembelajaran yang menyenangkan.

Zuchdi dalam Setiono (1994:11) menyebutkan bahwa model pembelajaran bahasa daerah dapat dirumuskan sebagai berikut:

1. Dalam pembelajaran bahasa daerah perlu ada buku Pedoman Pengajaran Bahasa Daerah untuk siswa PAUD sampai dengan Perguruan Tinggi. Buku ini mengajarkan model pembelajaran bahasa daerah berdasarkan pendekatan komunuikatif.

2. Strategi pembelajaran bahasa daerah berciri pada:

Seni permainan untuk meningkatkan motivasi intrinsik siswa. 
- Didominasi bentuk praktek untuk mengaktifkan siswa.

- Menempatkan siswa sebagai pusat

- Model pembelajaran bahasa yang menyenangkan.

Kalau dalam bahasa Bali dapat diakronimkan di sini dengan BASBIM (maksudnya: Bahasa Bali yang Menyenangkan). Strategi BASBIM juga dapat dirangkum dalam 4 (empat) model, yaitu: Bermain kata, Bermain peran, kuis bahasa, dan olah (utak-atik) aksara Bali.

Model pembelajaran yang pertama yaitu dengan bermain kata dapat diterapkan untuk tujuan meningkatkan penguasaan kosa kata bahasa Bali para peserta didik, baik yang tergolong kosa kata bahasa Bali alus (alus singgih, alus mider, alus sor) maupun kosa kata bahasa Bali lumrah, kasar, andap, dan jabag. Dari strategi ini para peserta didik secara langsung dapat mempelajari dan mengetahui tingkatan-tingkatan bahasa Bali yang populer disebut anggah ungguh basa Bali.

Menurut Edi Setyanto (badan bahasa kemendikbud.go.id) mengatakan model pembelajaran pertama yaitu bermain kata dapat terwujud dalam dua strategi, yaitu: teka- teki silang (TTS) dan skrebel. Peranti yang diperlukan adalah lembar TTS atau lembar skrebel. Dalam pembelajaran bahasa Bali model ini dapat diejawantahkan lagi dengan bermain paribasa Bali (seperti: bladbadan, peparikan, cecangkriman, cecangkikan, sesawangan, wewangsalan, sesonggan, cecimpedan, dan lain sebagainya).

Model pembelajaran yang kedua yaitu bermain peran diterapkan untuk meningkatkan penguasaan kota kata, penguasaan gramatika, kemampuan bicara, dan kemampuan mengapresiasi sastra. Model bermain peran terwujud dalam dua strategi yaitu (1) bermain sandiwara dan (2) berbicara monolog dalam forum resmi dan tidak resmi. Peranti yang diperlukan adalah (penggalan) naskah sandiwara atau teks monolog. Bermain peran sangat cocok untuk melatih kemampuan aksen berbahasa daerah sebagai salah satu kekhasan sebuah bahasa. Pelatihan aksen itu menjadi penting mengingat banyak generasi muda yang sudah kehilangan aksen bahasa ibu. Dalam pembelajaran bahasa Bali para pengajar (baca guru) dapat melatih anak-anak untuk mementaskan naskah-naskah drama 
berbahasa Bali, bercerita (masatua Bali), tampil berpidato (mapidarta Bali), berapresiasi, musikalisasi, dan dramatisasi berpuisi-puisi Bali modern. Lain daripada itu latihan juga dapat dilakukan melalui satu kegiatan seni tradisi dalam bentuk sekaa pasantian ( satu perkumpulan para penggemar membaca, menembang, mengartikan atau ngartos, mengulas, dan memaknai nilai-nilai luhur yang terkandung dalam karya-karya sastra Bali tradisional baik yang berbentuk kekawin, kidung, maupun geguritan).

Kemudian pada model pembelajaran yang ketiga, kuis bahasa, menurut Setyanto diterapkan untuk meningkatkan kemampuan menyimak sumber tulis dan lisan dalam bahasa daerah. Model ini terwujud dalam tiga strategi, yaitu (1) kuis berita, (2) mengubah lagu, dan (3) cerdas tangkas. Peranti yang diperlukan berupa fotocoy teks berita atau CD (jika strategi yang dipilihnya itu berupa teks berita), lagu yang akan diubah ke dalam bahasa daerah (jika strategi yang dipilih berupa strategi mengubah lagu), dan papan skor pengatur waktu, lembar pertanyaan, dan kertas padalarang (jika yang dipilih itu berupa strategi cerdas tangkas). Dalam menumbuhkembangkan strategi pembelajaran Bahasa Bali yang lebih bermakna, maka melalui model pembelajaran yang ketiga ini dapat dilakukan dengan cara menyimak Gatra Bali, menyimak wacana berbahasa Bali, menyimak satua-satua Bali, membuat pupuh-pupuh/sekar macepat, dan juga mengadakan kegiatan saur-pitaken baik yang bersifat perorangan maupun antar kelompok. Mengubah lagu-lagu Pop Indonesia ke dalam bahasa Bali adalah juga menjadi faktor penentu keberhasilan model pembelajarannya. Mengubah lagu ini dapat dilakukan dengan menggunakan anggah ungguh basa Bali yang baik dan benar. Cerdas tangkas dan debat mabasa Bali (berdebat dengan menggunakan bahasa Bali).

Terakhir, model pembelajaran keempat yaitu utak-atik aksara. Model pembelajaran ini diterapkan untuk tujuan meningkatkan kemampuan siswa dalam membaca dan menulis akara Bali. Dalam mata pelajaran bahasa Bali diperkenalkan beberapa pustaka Bali tradisional berupa lontar yang isinya bermacam-macam antara lain ada yang tergolong Weda (Catur Weda), 
Japa/Mantra, Itihasa/Wiracarita, Purana, Usadha, Babad, Tantri, Lelampahan, dan lain-lain. Ada pula beberapa pustaka yang sudah diterbitlan dalam bentuk buku berupa kekawin, kidung, geguritan, serta satua-satua (cerita-cerita) berbahasa Bali.

Dalam bidang penulisan, para perserta didik diperkenalkan ragam aksara Bali (Aksara modre, Aksara Swalalita, Aksara Wrehastra, Aksara Suara, dan aksara Wyanjana). Demikian pula halnya dengan Pangangge Aksara, Warga Aksara, dan Pasang Pageh). Cara-cara/tatacara/aturan menulis bahasa Bali dengan aksara Bali disebut dengan Uger-uger nyurat aksara Bali. Para peserta didik yang memahami uger-uger ini dianggap mampu menguasai Pasang Aksara Bali dengan baik dan benar. Dari kemampuan inilah selanjutnya dapat dilakukan latihan-latihan menulis lontar, alih aksara dari aksara Bali ke latin dan sebaliknya, serta membuat karangan berbahasa Bali dengan menggunakan aksara Bali. Model keempat inilah yang sarat menuntun para peserta didik dapat meningkatkan kemampuan dan keterampilan mereka dalam membaca dan menulis aksara Bali.
Pada dasarnya penerapan keempat model pembelajaran di atas tidak saja sangat menarik bagi peserta didik di satu pihak, akan tetapi juga menguntungkan bagi para guru, institusi di pihak lain. Bahkan lebih daripada itu dapat menumbuhkan kembali rasa cinta dan rasa memiliki dari masyarakat Bali terhadap bahasa daerahnya sendiri (Santika, 2019). Bahasa Bali akan menjadi tetap hidup dan tetap diajarkan sebagai salah satu bentuk kearifan lokal Bali dalam menunjang dan memperkokoh kebudayaan daerah Bali di tengah-tengah hingar bingar pesatnya perkembangan budaya global.

\section{SIMPULAN}

Bahasa Bali merupakan salah satu bahasa daerah di Indonesia yang dilindungi dan dipelihara oleh negara. Dalam amanat perubahan keempat UUD 1945 Bab XIII Pasal 32, dinyatakan bahwa negara menghormati dan memelihara bahasa daerah sebagai kekayaan budaya nasional. Menjunjung tinggi amanat dari perubahan tersebut, maka Pemerintah Provinsi Bali juga menerbitkan satu peraturan yang dinamakan Peraturan Gubernur Nomor 80 Tahun 2018 tentang Perlindungan dan 
Penggunaan Bahasa, Aksara, Sastra Bali, dan Penyelenggaraan Bulan Bahasa Bali.

Sebagai salah satu aspek dari kebudayaan Bali, maka bahasa daerah Bali memegang peranan sangat penting dalam menunjang behasa dan kebudayaan nasional. Oleh karena itu, maka keberadaan bahasa daearah Bali sampai saat ini masih tetap hidup dan terus diajarkan di dalam lingkungan pendidikan formal dari tingkat pendidikan dasar sampai ke tingkat perguruan tinggi.

Model pembelajaran bahasa Bali yang diterapkan dalam dunia pendidikan formal selama ini perlu dikembangkan ke arah model pembelajaran yang lebih bermakna, komunikatif, menarik, menyenangkan, dan tidak membosankan (strategi BASBIM : Bahasa Bali yang Menyenangkan). Cara-cara yang perlu ditempuh untuk hal itu dapat dirumuskan melalui empat model pembelajaran yaitu bermain kata, bermain peran, kuis bahasa dan sastra Bali, dan olah (utak-atik) aksara Bali. Selain itu dapat pula dilengkapi dengan menerapkan pendekatan Contextual Teaching and Learning, Komunikatif - Intgeraktif, dan terintegralistik.

\section{DAFTAR PUSTAKA}

Efendi, Anwar. 2008. Bahasa \& Sastra Dalam Berbagai Perspektif. Yogyakarta: Tiara Kencana bekerjasama dengan Fakultas Bahasa Dan Seni Universitas Negeri Yogyakarta.

Emzir dan Rohman, Saifur. 2015. Teori dan Pengajaran Sastra. Jakarta: PT Raja Grafindo Prasada.

Gautama, Wayan Budha. 2006. Tata Sukerta Basa Bali. Denpasar: CV. Kayumasagung.

Ghazali,Syukur. 2013. Pembelajaran Keterampilan Berbahasa Dengan Pendekatan Komuniukatif-Interaktif. Bandung: PT. Refika Aditama.

Guntur Tarigan, Henry. 1991. Metode Pengajaran Bahasa 1. Bandung: Angkasa.

Iskjandarwassid dan Sunendar, Dadang. 2013. Strategi Pembelajaran Bahasa. Bandung: Sekolah Pascasarjana Universitas Pendidikan Indonesia dengan PT Remaja Rosdakarya.

Mulyana, Ed. 2008. Pembelajaran Bahasa dan Sastra Daerah Dalam Kerangka Budaya. Yogyakarta: Tiara Wacana.

Sagala, Syaiful. 2007. Konsep dan Makna Pembelajaran. Bandung: Alfabeta.

Santika, I. G. N., Rindawan, I. K., \& Sujana, I. G. (2019). Memperkuat Pancasila Melalui Pergub No. 79 Tahun 2018 Dalam Menanggulangi Pengikisan Budaya Di Era Revolusi Industri 4.0. Prosiding Seminar Nasional Inobali 2019, 79, 981-990

Setyanto, Edi. tt. "Model Pembelajaran dan Pelestarian Bahasa Daerah." Jakarta: Badan Pengembangan dan PembinaanBahasa Kementerian Pendidikan dan Kebudaayan.

Smith, Mark K. dkk. 2010. Teori Pembelajaran dan Pengajaran. Jogjakarta: Mirza Media Pusaka.

Trianto, 2012. Mendesain Model Pembelajaran Inovatif - Progresif. Jakarta: Kencana Prenada Media Gorup. 
Wayan Swarniti, N. (2019). The Translation

Procedures of Bible Translation.

5(2), 187-196.

https://doi.org/10.22225/jr.5.2.1277.

187-196

Zuchdi, 1994 "Pendekatan Komunikatif

Dalam Pengajaran Bahasa:

Pengertian dan Karakteristik".

Makalah Penataran dan Pelatihan

Pengajaran Bahasa Indonesia yang

Bersifat Komunikatif. Yogyakarta :

FPBIS, IKIP, 18-24 Juli

1994. 